İşletme Akademisi Dergisi
2021,2 (1): $94-102$.
DOl:10.26677/TR1010.2021.703
Dergi web sayfasl: www.isakder.org

Araştırma Makalesi

\title{
Lisans Düzeyi Muhasebe Dersi Öğrencilerinin Muhasebe Etiği Algısı: Mardin Artuklu Üniversitesi İşletme ve İktisat Bölümleri Öğrencileri Üzerine Bir Araştırma*
}

\section{Dr. Öğr. Üyesi Osman Nuri ŞAHİN}

Alanya Alaaddin Keykubat Üniversitesi, İ̈BF İşletme Bölümü, Antalya. osmannurisahin@yahoo.com, www.orcid.org/0000-0002-6586-7073

Öz

Muhasebe skandalları ile birlikte muhasebe alanında etik kavramı yeniden sorgulanmaya başlamıştır. Muhasebede meslek mensuplarınca üretilen bilgiler günlük finansal hayatta tüm ilgililer açısından büyük öneme sahiptir. Bu açıdan muhasebe meslek mensuplarının mesleki faaliyetlerinde etik ilkeleri takip etmeleri gerekmektedir. Lisans düzeyinde mesleğe yönelik eğitim meslek hayatının en önemli basamaklarındandır. Eğitim aşamasında muhasebede etik konusunun nasıl algılandı̆̆ının ele alınması eğitimin etik çerçevesinde şekillendirilmesine fayda sağlayacaktır. Bu çalışmanın amacı lisans düzeyinde muhasebe dersi alan öğrencilerin muhasebe etiğini algılarının tespit edilmesidir. Bu kapsamda Mardin Artuklu Üniversitesi İktisadi ve İdari Bilimler Fakültesinde muhasebe dersi alan İşletme ve İktisat bölümü öğrencileri üzerinde bir araştırma yapılmıştır. Toplanan veriler ile istatistiki olarak analize tabi tutulmuştur.

* Bu makale 1. Al Farabi Uluslararası Sosyal Bilimler Kongresinde bildiri olarak sunulan ve özet olarak kongre kitabında basılan çalışmanın daha sonrasında genişletilmesi ve geliştirilmesi ile türetilmiştir.

Anahtar Kelimeler: Muhasebe, Etik, Lisans Öğrencileri, Eğitim.

Makale Gönderme Tarihi: 13.01.2021

Makale Kabul Tarihi: 28.01.2021

\section{Önerilen Atıf:}

Şahin, O. N. (2021). Lisans Düzeyi Muhasebe Dersi Öğrencilerinin Muhasebe Etiği Algısı: Mardin Artuklu Üniversitesi İşletme ve İktisat Bölümleri Öğrencileri Üzerine Bir Araştırma, Isşletme Akademisi Dergisi, 2(1): 94-102.

(c) 2021 İşletme Akademisi Dergisi. 


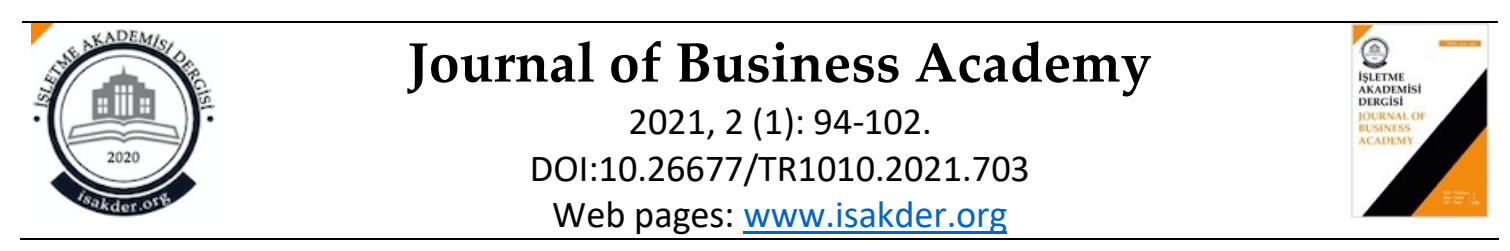

Research Article

\title{
Accounting Ethics Perception of Undergraduate Accounting Course Students: A Research on the Students of Mardin Artuklu University Business Administration and Economics Departments
}

\author{
Assistant Prof. Dr. Osman Nuri ŞAHIN \\ Alanya Alaaddin Keykubat University, Faculty of Economics and Administrative \\ Sciences, Department of Business Administration, Antalya.
} osmannurisahin@yahoo.com,www.orcid.org/0000-0002-6586-7073

\begin{abstract}
With the accounting scandals, the concept of ethics in the field of accounting has started to be questioned again. The information produced by the accounting professionals is of great importance in daily financial life for all concerned. In this respect, professional accountants should follow ethical principles in their professional activities. Training for the profession at the undergraduate level is one of the most important steps of professional life. Discussing how the ethical issue in accounting is perceived during the education phase will help to shape the education within the ethical framework. The aim of this study is to determine the perceptions of the students who take the accounting course at the undergraduate level. In this context, research was conducted on the students of the Department of Business Administration and Department of Economics, who took accounting courses at the Faculty of Economics and Administrative Sciences, Mardin Artuklu University. The collected data statistically analyzed.
\end{abstract}

Keywords: Accounting, Ethics, Undergraduate Students, Education.

Received: 13.01 .2021

Accepted: 28.01.2021

\section{Suggested Citation:}

Şahin, O. N. (2021). Accounting Ethics Perception of Undergraduate Accounting Course Students: A Research on the Students of Mardin Artuklu University Business Administration and Economics Departments, Journal of Business Academy, 2(1): 94-102.

(C) 2021 Journal of Business Academy. 


\section{Gİiş}

Ekonomik hayattaki yeri ve kapsayıcılığı sebebiyle muhasebede etik ilkeler büyük bir öneme sahiptir. Ekonomik hayatı iyileştirmenin yollarından biri de muhasebe alanında etik ilkelerin uygulanmasıdır. 2007 yılında 26675 sayılı Resmî Gazete'de yayınlanan “Serbest Muhasebeciler, Serbest Muhasebeci Mali Müşavirler ve Yeminli Mali Müşavirlerin Mesleki Faaliyetlerinde Uyacakları Etik İlkeler Hakkında Yönetmelik" ile meslek etik ilkeleri dürüstlük, tarafsızlık, mesleki yeterlilik ve özen, gizlilik, mesleki davranış olarak belirlenmiştir. Bu ilkelerin meslek mensuplarınca uygulanmasının temelinin atılmasındaki en önemli adımlardan biri de eğitimdir. Meslek mensuplarının yetiştirilmesi sırasında etik ilkelere bağlılığın temelinin atılması ileride bu ilkelere bağlı bireylerin sayısını artıracaktır. Bu sayede ekonomik hayatın gelişiminin etik dışı davranış ve faaliyetler ile yavaşlamasına önleyecek meslek mensupları yetiştirilebilecektir. Muhasebe eğitiminin önemli bir adımı da lisans düzeyindeki eğitimdir. Özellikle lisans düzeyinde muhasebe etik algısının bu açıdan incelenerek analiz edilmesi ve yeni yaklaşımların geliştirilmesi faydalı olacaktır. Bu çalışma ile muhasebe dersi alan öğrencilerin muhasebe etiği algılarının araştırılması amaçlanmaktadır.

\section{LİTERATÜR TARAMASI}

Literatüre göz atıldığında muhasebede etiğe yönelik farklı kesimler üzerinde çalışmalar yapıldığı görülmektedir. Uçma (2007) işletme bölümü öğrencilerine yönelik çalışmasında, muhasebe alanındaki mesleki etiğin gelişmesinde ilk sırada üniversite eğitimi olduğunu ve öğrencilerin muhasebe meslek etiği ile ilgili müfredatta zorunlu bir ders istendiğini tespit etmiştir. Ayrıca katılımcıların çoğunluğunun "En iyi muhasebeci en az vergi ödeten muhasebecidir" ifadesinin etik olmadığı konusunda hemfikir olduğu sonucuna ulaşmıştır. Altuk (2006) işletme bölümü öğrencilerine yönelik çalışmasında muhasebe dersi alan öğrencilerin çoğunluğunun muhasebe etiğine yönelik ders almadıklarını tespit etmiştir. Altuk (2006) çalışmasında öğrencilerin söz konusu dersin faydalı olduğunu düşündükleri sonucunu elde ederken Ghaffari vd., (2008) muhasebe-finans bölümü bulunan İngiliz üniversitelerine yönelik çalışmalarında ve Ağyar vd., (2012) ön lisans öğrencilerine yönelik çalı̧̧malarında benzer bir sonuçla muhasebe etiğinin müfredatta yer alması gerektiği sonucunu elde etmişlerdir. Kurnaz ve Gümüş (2010) muhasebe dersi alan öğrencilere yönelik çalışmalarında kız öğrencilerin etik algılarının erkek öğrencilere ve üst sınıf öğrencilerinin etik algılarının alt sınıf öğrencilerine göre farklılaştığını görmüştür. Ayrıca ikamet yeri ile öğrencilerin etik dışı olay algılarında anlamlı bir farklılık içinde olmadığ sonucuna ulaşmışlardır. Akyatan ve Kutluk (2015) çalışmalarında kız öğrencilerin erkeklere göre daha yüksek yargı puanına sahip olduğunu ve muhasebe etiği dersi alan öğrencilerle almayan öğrencilerin etik yargıların farklılaştı̆̆ 1 görülmüştür. Blanthorne vd. (2007), muhasebe öğretim üyelerine yönelik çalışmalarında katılımcıların \%95'inin muhasebe öğrencilerinin etik eğitimi alması gerektiğini düşündükleri sonucuna varmışlardır.

Konuya ilişkin muhasebe dersi alan ön lisans öğrencileri düzeyinde yapılan çeşitli çalışmalar bulunmaktadır. Bunlardan Ay ve Güler (2011) çalışmalarında kız öğrencilerin erkek öğrencilere göre daha yüksek etik yargı seviyesine sahip olduklarını tespit etmişlerdir. Ağyar vd., (2012) de çalışmalarında benzer bir sonuçla etik hassasiyet açısından kız öğrencilerin erkeklerden daha duyarlı bir etik hassasiyete sahip oldukları sonucuna ulaşmışlardır. Ek olarak etik dersi almış öğrencilerin etik yargılarının almamış öğrencilere göre daha etik olduğunu tespit etmişlerdir. Ay ve Güler (2011) aynı çalışmalarında gelir düzeyi ile öğrencilerin etik yargı seviyesi arasında istatistiksel olarak anlamlı bir farklılığın olmadığını tespit etmişlerdir. Fakat ikamet yerinin etik yargı seviyesi ile istatistiki açıdan anlamlı bir farklılık içinde olduğunu tespit etmişlerdir. Uyar vd. (2015) ise çalışmalarında öğrenciler tarafından mesleki açıdan muhasebede etik dışı 
uygulamaların olduğuna yönelik bir algıya sahip olduklarını tespit etmişlerdir. Diğer taraftan aynı çalışmada meslek etiği ile ilgili dersi alanlar ile almayanların meslek etiği algılarında anlamlı bir farklılık olmadığı sonucunu elde etmişlerdir. Çavuşoğlu ve Kutluk'un (2016) çalışmalarında ise öğrencilerin cinsiyetleri, sınıfları, ikamet yerleri ve aile gelir düzeylerinin muhasebede etik yargılarından bazıları ile istatistiki olarak anlamlı bir farklılık içinde olduğu sonucuna ulaşılmıştır. Aynı çalışmada katılımcıların en çok "Muhasebe meslek mensubu gerekli mesleki bilgi ve donanıma sahip olmalıdır" yargısına katılırken en çok "En iyi muhasebeci en az vergi ödeten muhasebecidir" yargısına kesinlikle katılmadıkları sonucu elde edilmiştir.

\section{ARAŞTIRMA YÖNTEMİ ve BULGULAR}

$\mathrm{Bu}$ çalışma ile muhasebe dersi alan öğrencilerin muhasebe etiği algılarının tespit edilmesi amaçlanmaktadır. Çalışmada veriler anket yöntemi ile toplanmıştır. Anket Çavuşoğlu ve Kutluk (2016) tarafından çeşitli çalışmalardan derlenerek oluşturulan muhasebe etiği yargılarından oluşmaktadır. Söz konusu anket Mardin Artuklu Üniversitesi İktisadi ve İdari Bilimler Fakültesi İşletme ve İktisat bölümü öğrencilerine uygulanmıştır. Bu bölümler müfredatları kapsamında muhasebe dersinin daha yoğun verildiği bölümler olmaları sebebiyle seçilmiştir. Katılımcıların cevaplarının doğru olduğu ve yönlendirilmedikleri varsayılmıştır. Anket muhasebe dersini alan öğrencilere yönelik muhasebe etiği algılarının tespitine yönelik 10 ifade barındırmaktadır. Söz konusu ifadelerin 5'li Likert ölçeği ile "Kesinlikle Katılmıyorum, Katılmıyorum, Fikrim Yok, Katılıyorum, Kesinlikle Katılıyorum" şeklinde cevaplanması istenmiştir. Eymen (2007) çalışmalarda parametrik testlerin uygulanabilmesi için gerekli iki şartı örneklem büyüklügünün 30 'dan büyük olması ve verilerin homojen olması ve normal dağılması olarak belirtmiştir. Bu çalışmada örneklem büyüklügünün 101'dir dolayısıyla ilk şart sağlanmıştır. Ancak normallik analizi sonrası Kolmogorov-Smirnov testi $p$ değerleri $(p=0,000)$ ve Shapiro-Wilk testi $p$ değerlerinin $(p=0,000) 0,05$ 'ten küçük olduğu, basıklık ve çarpıklık değerlerinin $-1,5$ ve $+1,5$ aralığında (Tabachnick ve Fidell, 2013) olmadığı görülmüş dolayısıyla verilerin normal dağılmadığı kabul edilmiştir. Bu sebeple çalışmadaki veriler içim parametrik olmayan yöntemlerden faydalanılmıştır. Anket kapsamında toplanan veriler SPSS 22.0 programı ile frekans analizi sonrası Man-Whitney U testi ve Kruskal-Wallis testlerine tabi tutulmuş ve demografik veriler ile muhasebe etiği algıları arasında istatistiki açıdan anlamlı farklılığın olup olmadığına bakılarak anlamlı farklılığın olduğu bulgulara çalışmada yer verilmiştir.

Uzunsakal ve Yıldız (2018) Cronbach Alfa değerlerinde 0,60-0,80 aralığını oldukça güvenilir olarak nitelendirmişlerdir. Soruların sayısı az ise sınır değeri olarak 0.60 ve üstü kabul edilebilir (Kayış, 2008:405). Araştırmada kullanılan yargıların Cronbach's Alfa değeri 0.697 olduğundan ölçeğin oldukça güvenilir olduğu kabul edilmiştir.

Çalışmaya katılan öğrencilerin \%56,4'ü 18-21 yaş aralığındayken, \%37,6'sı 22-25, \%5,9'u 26-29 yaş aralığındadır. 30 yaş ve üstü katılımcının olmadığı görülmektedir. Katılım gösteren öğrencilerin cinsiyetlerine bakıldığında \%54,5 ile yarıdan fazla katılımcının kadın, \%45,5'inin ise erkek olduğu görülmüştür. Katılımcıların bölümlerine bakılacak olursa \%35,6'sının işletme bölümü öğrencisi olduğu, diğer \%64,4'ünün ise iktisat bölümü öğrencisi olduğu görülmektedir. Ankete katılan öğrencilerin \%67,3 ile çoğunluğu birinci sınıf öğrencisidir. Kalan öğrencilerin \%29,7'si dördüncü sınıf öğrencisiyken, 2,3 ve 5. sınıf öğrencisi birer kişi bulunmaktadır. Mezun olunan lise türü açısından katılımcıların çoğunluğunu temsil eden $\% 61,4^{\prime} \ddot{u}$ düz lise mezunudur. Kalanların $\% 20,8^{\prime} \mathrm{i}$ anadolu lisesi, \%11,9'u meslek lisesi, \%5'i özel lise, \%1'i ise fen lisesi mezunudur. Öğrencilerin \%49,5 ile yarısına yakını büyükşehirlerde yaşamaktadır. Kalanların \%33,7'si 'ü şehirlerde, \%11,9'u ilçelerde ve \%5'i köy ya da kasabalarda ikamet etmektedir. Öğrencilerin $\% 32,7^{\prime}$ si daha önce muhasebe dersi almıştır. Kalan \%67,3'ü ise muhasebe dersi almamıştır. 
Öğrencilerin \%87,1'i aldığı muhasebe dersini zorunlu almıştır. Kalan \%12,9'u ise seçmeli olarak almıştır. Öğrencilerin \%52,5'inin yakın çevresinde muhasebe mesleğini yapan birisi bulunmaktadır. Kalan \%47,5'inin ise yakın çevresinde muhasebe mesleğini yapan birisi bulunmamaktadır.

Tablo 2. Demografik Veriler

\begin{tabular}{|c|c|c|c|c|c|}
\hline & & Frekans & Yüzde & $\mathbf{n}$ & $\%$ \\
\hline \multirow{5}{*}{ Yaş } & $18-21$ & 57 & 56,4 & \multirow{5}{*}{101} & \multirow{5}{*}{100} \\
\hline & $22-25$ & 38 & 37,6 & & \\
\hline & $26-29$ & 6 & 5,9 & & \\
\hline & $30-33$ & 0 & 0,0 & & \\
\hline & $33 \leq$ & 0 & 0,0 & & \\
\hline \multirow{2}{*}{ Cinsiyet } & Kadın & 55 & 54,5 & \multirow{2}{*}{101} & \multirow{2}{*}{100} \\
\hline & Erkek & 46 & 45,5 & & \\
\hline \multirow{2}{*}{ Bölüm } & İşletme & 36 & 35,6 & \multirow{2}{*}{101} & \multirow{2}{*}{100} \\
\hline & İktisat & 65 & 64,4 & & \\
\hline \multirow{5}{*}{ Sinif } & 1 & 68 & 67,3 & \multirow{5}{*}{101} & \multirow{5}{*}{100} \\
\hline & 2 & 1 & 1,0 & & \\
\hline & 3 & 1 & 1,0 & & \\
\hline & 4 & 30 & 29,7 & & \\
\hline & 5 & 1 & 1,0 & & \\
\hline \multirow{5}{*}{ Mezun Olunan Lise Türü } & Düz Lise & 62 & 61,4 & \multirow{5}{*}{101} & \multirow{5}{*}{100} \\
\hline & Anadolu Lisesi & 21 & 20,8 & & \\
\hline & Fen Lisesi & 1 & 1,0 & & \\
\hline & Özel Lise & 5 & 5,0 & & \\
\hline & Meslek Lisesi & 12 & 11,9 & & \\
\hline \multirow{4}{*}{$\begin{array}{c}\text { Yaşanılan Yerleşim Yeri } \\
\text { Türü }\end{array}$} & Köy/Kasaba & 5 & 5,0 & \multirow{4}{*}{101} & \multirow{4}{*}{100} \\
\hline & İlçe & 12 & 11,9 & & \\
\hline & Şehir & 34 & 33,7 & & \\
\hline & Büyük Şehir & 50 & 49,5 & & \\
\hline \multirow{2}{*}{$\begin{array}{l}\text { Daha Önce Muhasebe Dersi } \\
\text { Aldınız mı? }\end{array}$} & Evet & 33 & 32,7 & \multirow{2}{*}{101} & \multirow{2}{*}{100} \\
\hline & Hayır & 68 & 67,3 & & \\
\hline \multirow{2}{*}{$\begin{array}{c}\text { Alınan Muhasebe Ders } \\
\text { Türü } \\
\end{array}$} & Zorunlu & 88 & 87,1 & \multirow{2}{*}{101} & \multirow{2}{*}{100} \\
\hline & Seçmeli & 13 & 12,9 & & \\
\hline \multirow{2}{*}{$\begin{array}{c}\text { Yakın Çevrenizde } \\
\text { Muhasebeci Var mı? }\end{array}$} & Evet & 53 & 52,5 & \multirow{2}{*}{101} & \multirow{2}{*}{100} \\
\hline & Hayır & 48 & 47,5 & & \\
\hline
\end{tabular}

Muhasebede etik algılara yönelik cevapların frekanslarına bakıldığında öğrencilerin en çok muhasebe meslek mensuplarının gerekli mesleki bilgi ve donanıma sahip olmaları gerektiğine kesinlikle katıldıkları görülmüştür. Bu ifadeyi takiben muhasebe meslek mensuplarının topluma tarafsız ve doğru bilgi sunmaları gerektiğine kesinlikle katıldıkları görülmektedir. Katılımcı öğrenciler en çok muhasebe meslek mensubunun müşterilerinden hiçbir şekilde hediye kabul etmemesi düşüncesine kesinlikle katılmamaktadırlar. Bu çerçevede hediye alınmasında bir sorun olmadığını, muhasebe meslek mensuplarının hediye kabul edebileceklerini düşündükleri sonucuna varılabilir. Bu ifade sonrası ise en çok meslek mensuplarının müşterileri ile sıkı arkadaşlık veya dostluk ilişkisi kurmamalı ifadesine kesinlikle katılmamaktadırlar. 
Tablo 3. Muhasebe Etiği Algısı İfadeleri

\begin{tabular}{|c|c|c|c|c|c|c|c|c|}
\hline & 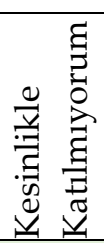 & 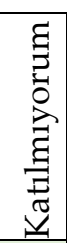 & 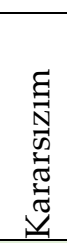 & 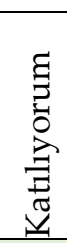 & 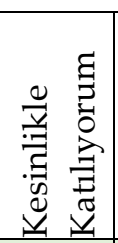 & $\begin{array}{l}\tilde{\sigma} \\
\frac{\pi}{2} \\
\frac{0}{0} \\
0\end{array}$ & $X$ & SS \\
\hline $\begin{array}{l}\text { En iyi muhasebeci en az vergi ödeten } \\
\text { muhasebecidir }\end{array}$ & 9 & 30 & 21 & 25 & 16 & 101 & 3,09 & 1,242 \\
\hline $\begin{array}{l}\text { Muhasebe meslek mensubu müşterisi ile } \\
\text { ücret dışında borç-alacak ilişkisi } \\
\text { kurmamalıdır }\end{array}$ & 9 & 23 & 24 & 38 & 7 & 101 & 3,11 & 1,113 \\
\hline $\begin{array}{l}\text { Muhasebe meslek mensubu } \\
\text { müşterisinden hiçbir şekilde hediye } \\
\text { kabul etmemelidir }\end{array}$ & 10 & 28 & 26 & 27 & 10 & 101 & 2,99 & 1,162 \\
\hline $\begin{array}{l}\text { Muhasebe meslek mensubu etik } \\
\text { davranış, sergilemek adına } \\
\text { müşterisinden gelecek baskılara karşı } \\
\text { koymalıdır }\end{array}$ & 2 & 9 & 18 & 49 & 23 & 101 & 3,81 & 0,956 \\
\hline $\begin{array}{l}\text { Muhasebe meslek mensubu daima } \\
\text { toplumun menfaatlerini, kendisinin ve } \\
\text { müşterisinin menfaatlerinden üstün } \\
\text { tutmalıdır }\end{array}$ & 6 & 13 & 30 & 30 & 22 & 101 & 3,49 & 1,146 \\
\hline $\begin{array}{l}\text { Muhasebe meslek mensubu topluma } \\
\text { tarafsız ve doğru bilgiler sunmalıdır }\end{array}$ & 3 & 4 & 4 & 36 & 54 & 101 & 4,33 & 0,950 \\
\hline $\begin{array}{l}\text { Muhasebe meslek mensubu müşterisi ile } \\
\text { sıkı arkadaşlık veya dostluk ilişkisi } \\
\text { kurmamalıdır }\end{array}$ & 7 & 30 & 26 & 26 & 12 & 101 & 3,06 & 1,147 \\
\hline $\begin{array}{l}\text { Muhasebe meslek mensubu müşterisi ile } \\
\text { ilgili bilgileri kendisine veya başkalarına } \\
\text { menfaat sağlamak için kullanmamalıdır }\end{array}$ & 6 & 4 & 11 & 33 & 47 & 101 & 4,10 & 1,127 \\
\hline $\begin{array}{l}\text { Muhasebe meslek mensubu gerekli } \\
\text { mesleki bilgi ve donanıma sahip } \\
\text { olmalıdır }\end{array}$ & 2 & 4 & 6 & 33 & 56 & 101 & 4,36 & 0,912 \\
\hline $\begin{array}{l}\text { Muhasebe meslek mensubu menfaat } \\
\text { çatışmalarında etik değerlere bağlı } \\
\text { kalmalıdır }\end{array}$ & 6 & 7 & 15 & 33 & 40 & 101 & 3,93 & 1,168 \\
\hline
\end{tabular}

Toplanan verilerin normal dağılmaması sebebiyle, demografik veriler ile meslek etiği algısı ifadeleri arasındaki anlamlı farklılığın tespit edilmesi amacıyla parametrik olmayan testler uygulanmıştır. 
Tablo 4. Muhasebe Etiği İfadeleri ve Cinsiyet Man-Whitney U Testi

\begin{tabular}{|c|c|c|c|c|c|c|}
\hline & Cinsiyet & $N$ & $\begin{array}{c}\text { Sira } \\
\text { Değerleri } \\
\text { Ortalamast }\end{array}$ & $U$ & Z & $p$ \\
\hline \multirow{2}{*}{$\begin{array}{l}\text { Muhasebe meslek mensubu } \\
\text { müşterisi ile sıkı arkadaşlık veya } \\
\text { dostluk ilişkisi kurmamalıdır }\end{array}$} & Kadın & 55 & 43,87 & \multirow{2}{*}{873,000} & \multirow{2}{*}{$-2,760$} & \multirow{2}{*}{0,006} \\
\hline & Erkek & 46 & 59,52 & & & \\
\hline
\end{tabular}
${ }^{*} \mathrm{p}<0,05$

Katılımcların cinsiyetleri ile "muhasebe meslek mensubunun müşterisi ile sıkı arkadaşlık veya dostluk ilişkisi kurmamalıdır" ifadesi arasında istatistiki açıdan anlamlı bir farklılık saptanmıştır $(\mathrm{p}=0,006 \mathrm{p}<0,05)$. Sonuca göre söz konusu ifadeye kadın katılımcılar erkeklerden daha az katılmaktadır. Meslek etiği algısı ifadelerinin diğerleri ile cinsiyet arasında anlamlı farklılık görülememiştir.

Tablo 5. Muhasebe Etiği İfadeleri ve Daha Önce Muhasebe Dersi Alıp Almama Man-Whitney U Testi

\begin{tabular}{|c|c|c|c|c|c|c|}
\hline & $\begin{array}{c}\text { Daha } \\
\text { Önce } \\
\text { Muhasebe } \\
\text { Dersi } \\
\text { Aldınız } \\
\text { mı? }\end{array}$ & $N$ & $\begin{array}{c}\text { Stra } \\
\text { Değerleri } \\
\text { Ortalaması }\end{array}$ & $U$ & Z & $p$ \\
\hline \multirow{2}{*}{$\begin{array}{l}\text { Muhasebe meslek mensubu } \\
\text { gerekli mesleki bilgi ve } \\
\text { donanıma sahip olmalıdır }\end{array}$} & Evet & 33 & 59,18 & \multirow[b]{2}{*}{852,000} & \multirow{2}{*}{$-2,193$} & \multirow[b]{2}{*}{0,028} \\
\hline & Hayır & 68 & 47,03 & & & \\
\hline
\end{tabular}

${ }^{*} \mathrm{p}<0,05$

Katılımcıların daha önceden muhasebe dersi almaları ile "Muhasebe meslek mensubu gerekli mesleki bilgi ve donanıma sahip olmalıdır" ifadesi arasında istatistiki açıdan anlamlı bir farklılık tespit edilmiştir $(\mathrm{p}=0,028 \mathrm{p}<0,05)$. Daha önce muhasebe dersi alanlar meslek mensuplarının gerekli donanıma sahip olmalarına daha çok katılmaktadırlar.

Tablo 6. Muhasebe Etiği İfadeleri ve Yaşanılan İkamet Birimi Man-Whitney U Testi

\begin{tabular}{|c|c|c|c|c|c|c|}
\hline & Grup & $N$ & $\begin{array}{l}\text { Sira } \\
\text { Değerleri } \\
\text { Ortalaması }\end{array}$ & $d f$ & $X^{2}$ & $p$ \\
\hline \multirow{5}{*}{$\begin{array}{c}\text { Muhasebe meslek mensubu müşterisi } \\
\text { ile sıkı arkadaşlık veya dostluk ilişkisi } \\
\text { kurmamalıdır }\end{array}$} & Köy/Kasaba & 5 & 42,30 & \multirow{5}{*}{3} & \multirow{5}{*}{9,906} & \multirow{5}{*}{0,019} \\
\hline & İlçe & 12 & 28,46 & & & \\
\hline & Şehir & 34 & 52,35 & & & \\
\hline & Büyük Şehir & 50 & 56,36 & & & \\
\hline & Toplam & $\begin{array}{l}10 \\
1\end{array}$ & & & & \\
\hline
\end{tabular}

${ }^{*} \mathrm{p}<0,05$ 
Öğrencilerin şu an yaşadıkları yerleşim biriminin muhasebe meslek mensubunun müşterileriyle sıkı arkadaşlık veya dostluk kurmaması gerektiğini düşünmeleri istatistiki olarak anlamlı bir farklılık içinde olduğu bulunmuştur $(\mathrm{p}=0,019 \mathrm{p}<0,05)$. Bu kapsamda söz konusu ifadeye en çok büyükşehirde yaşayan öğrenciler katılırken en az ilçelerde yaşayanlar katılmaktadır.

Ankete katılan öğrencilerin yaşları, sınıfları, bölümleri, mezun oldukları lise türü, yakın çevrelerinde muhasebeci olup olmamasının, muhasebe dersini zorunlu ya da seçmeli almaları, mezun olunca muhasebeci olmak istemeleri ile muhasebe etiği algıları arasında ise istatistiki açıdan anlamlı bir farklılık tespit edilememiştir.

\section{SONUÇ}

Muhasebe skandalları ile büyük çaplı ekonomik krizle etik konusunun önemini bir kez daha gündeme taşımıştır. Muhasebe meslek mensuplarının etik ilkelere bağlı olmasının temelinin bir bölümünün de muhasebe eğitimi sırasında atıldığı söylenebilir. Muhasebe eğitimi alan öğrencilerin muhasebe etiği algılarının araştırılması ve böylece bu konuya ilişkin gerekli adımların atılması muhasebede etik ilkelere bağlılığın sağlanması açısından önemlidir. Bu çalışmada muhasebe dersi alan öğrencilerin muhasebe etik algısı araştırılarak veriler analiz edilmiştir. Katılımcıların muhasebede etik açısından en çok muhasebe meslek mensuplarının gerekli mesleki bilgi ve donanıma sahip olmaları gerektiğine kesinlikle katıldıkları görülmüştür. Diğer taraftan en çok muhasebe meslek mensubunun müşterilerinden hiçbir şekilde hediye kabul etmemesi düşüncesine kesinlikle katılmamaktadırlar.

Katılımcıların cinsiyetleri ile muhasebe meslek mensubunun müşterisi ile sıkı arkadaşlık veya dostluk ilişkisi kurmamalıdır ifadesi arasında istatistiki açıdan anlamlı bir farklılık saptanmıştır $(\mathrm{p}=0,006 \mathrm{p}<0,05)$. Sonuca göre söz konusu ifadeye kadın katılımcılar erkeklerden daha az katılmaktadır. Bu da kadın katılımcıların sadece bu ifade çerçevesinde etik algılarının erkeklerden daha az olduğunu göstermektedir. Daha önce muhasebe dersi alıp almama ile "Muhasebe meslek mensubu gerekli mesleki bilgi ve donanıma sahip olmalıdır" ifadesi arasında istatistiki açıdan anlamlı bir farklılık tespit edilmiştir $(\mathrm{p}=0,028 \mathrm{p}<0,05)$. Daha önce muhasebe dersi alanlar meslek mensuplarının gerekli donanıma sahip olmalarına daha çok katılmaktadırlar. Öğrencilerin yaşadıkları yerleşim biriminin muhasebe meslek mensubunun müşterileriyle sıkı arkadaşlık veya dostluk kurmaması gerektiğini düşünmeleri istatistiki olarak anlamlı bir farklılık içinde olduğu bulunmuştur ( $p=0,019 \mathrm{p}<0,05)$. Söz konusu ifadeye en çok büyükşehirde yaşayan öğrenciler katılırken en az ilçelerde yaşayanlar katılmaktadır. Ankete katılan öğrencilerin yaşları, sınıfları, bölümleri, mezun oldukları lise türü, yakın çevrelerinde muhasebeci olup olmamasının, muhasebe dersini zorunlu ya da seçmeli almaları, mezun olunca muhasebeci olmak istemeleri ile muhasebe etiğine bakış açıları arasında istatistiki açıdan anlamlı bir farklılık tespit edilememiştir.

Çalışmanın kısıtlarına bakılacak olursa çalışmanın sadece işletme ve iktisat bölümlerine uygulanması kısıtlardan biridir. İleriki çalışmalarda muhasebe dersini en az bir kez alan tüm bölümlere uygulanması faydalı olacaktır. Çalışmada toplanan verilerde sınıf dağılımı birinci ve dördüncü sınıflarda yığılmıştır. İleriki çalışmalarda her sınıftan öğrencinin denk bir şekilde katılımının sağlanması daha anlamlı sonuçların elde edilmesine imkân tanıyabilir.

\section{KAYNAKÇA}

Ağyar, E., Kutluk, F. A. ve Cengiz, E. (2012). Meslek Yüksekokulları Muhasebe Bölümü Öğrencilerinin Sosyo-Ekonomik Değişkenler Işığında Mesleki Etiğe Bakış Açılarının İncelenmesi (Akdeniz Üniversitesi Örneği). Journal of Yaşar University, 7 (25), 4203-4228. 
Akyatan, A. ve Kutluk, F. A. (2015). Muhasebe Dersi Alan Öğrencilerin Etik Karar Alma Sürecini Etkileyen Faktörler Üzerine Bir Araştırma. Journal of Accounting, Finance and Auditing Studies, 1(4), 42-66.

Altuk, V. E. (2006). Türkiye'de Muhasebe Etiği Eğitimi. (Yüksek Lisans Tezi). Trakya Üniversitesi, Sosyal Bilimler Enstitüsü, Edirne.

Ay, M. ve Güler, E. (2011). Öğrencilerin Etik Değerleri: Meslek Yüksekokulu Öğrencilerine Yönelik Bir Araştırma. III. Ulusal Kurumsal Yönetim, Yolsuzluk, Etik ve Sosyal Sorumluluk Konferansı, 8-9 Haziran 2011, Nevşehir, Türkiye.

Blanthorne, C., Kovar, S. E. and Fisher, D. G. (2007). Accounting Educators' Opinions about Ethics in The Curriculum: An Extensive View. Issues in Accounting Education, 22(3), 355-390.

Çavuşoğlu, K. ve Kutluk, F. A. (2016). Meslek Yüksekokulunda Muhasebe Dersi Alan Öğrencilerin Muhasebe Etiğgine Bakış Açılarının Tespitine Yönelik Bir Araştırma: Anamur MYO Örneği. Uluslararası Alanya İşletme Fakültesi Dergisi, 8(2), 109-120.

Eymen, U. E. (2007). SPSS 15.0 Veri Analiz Yöntemleri, http://yunus.hacettepe.edu.tr/ tonta/courses/spring2009/bby606/SPSS_15

.0_ile_Veri_Analizi.pdf (Erişim Tarihi: 25.06.2020)

Ghaffar1, F., Kyriacou, O. and Brennan, R. (2008). Exploring the Implementation of Ethics in U.K. Accounting Programs. Issues in Accounting Education, 23(2), 183-198.

Kayış, A. (2008). SPSS Uygulamalı Çok Değişkenli İstatistik Teknikleri, (Ed.) KALAYCI, Ş., Asil Yayın Dağıtım, 3. Baskı, Ankara.

Kurnaz, N. ve Gümüş, Y. (2010). Muhasebe Bölümü Öğrencilerinin Muhasebe Mesleği ile İlgili Etik Dışı Davranışlara İlişkin Algı Analizi: Dumlupınar Üniversitesi Uygulamalı Bilimler Yüksekokulu Örneği. Muhasebe ve Finansman Dergisi, (46), 157-174.

Serbest Muhasebeciler, Serbest Muhasebeci Mali Müşavirler ve Yeminli Mali Müşavirlerin Mesleki Faaliyetlerinde Uyacakları Etik İlkeler Hakkında Yönetmelik., T.C. Resmi Gazete, 26675, 19 Ekim 2007.

Tabachnick, B. G., and Fidell, L. S. (2013). Using multivariate statistics (6th ed.). Boston: Allyn and Bacon.

Uçma, T. (2007). Muhasebe Meslek Mensubu Olmak İsteyenlerin Etik Değer Anlayışlarının Belirlenmesi ve Muğla Üniversitesi Uygulaması. (Yüksek Lisans Tezi). Muğla Üniversitesi, Sosyal Bilimler Enstitüsü, Muğla.

Uyar, S., Kahveci, A. ve Yetkin, M. (2015). Öğrencilerin Muhasebe Meslek Etiği Algısı: ALTSO Meslek Yüksekokulu Örneği. Niğde Üniversitesi İktisadi ve İdari Bilimler Fakültesi Dergisi, 8(1), 237-247.

Uzunsakal, E. ve Yıldız, D. (2018). Alan Araştırmalarında Güvenilirlik Testlerinin Karşılaştırılması ve Tarımsal Veriler Üzerine Bir Uygulama. Uygulamalı Sosyal Bilimler Dergisi, 2(1), 14-28. 